\title{
Review and Development of Electric Motor Systems and Electric Powertrains for New Energy Vehicles
}

\author{
William Cai ${ }^{1} \cdot{\text { Xiaogang } \mathrm{Wu}^{1} \cdot \text { Minghao Zhou }^{1} \cdot \text { Yafei Liang }}^{2} \cdot$ Yujin Wang $^{3}$
}

Received: 27 July 2020 / Accepted: 27 January 2021 / Published online: 25 February 2021

(c) The Author(s) 2021

\begin{abstract}
This paper presents a review on the recent research and technical progress of electric motor systems and electric powertrains for new energy vehicles. Through the analysis and comparison of direct current motor, induction motor, and synchronous motor, it is found that permanent magnet synchronous motor has better overall performance; by comparison with converters with Si-based IGBTs, it is found converters with SiC MOSFETs show significantly higher efficiency and increase driving mileage per charge. In addition, the pros and cons of different control strategies and algorithms are demonstrated. Next, by comparing series, parallel, and power split hybrid powertrains, the series-parallel compound hybrid powertrains are found to provide better fuel economy. Different electric powertrains, hybrid powertrains, and range-extended electric systems are also detailed, and their advantages and disadvantages are described. Finally, the technology roadmap over the next 15 years is proposed regarding traction motor, power electronic converter and electric powertrain as well as the key materials and components at each time frame.
\end{abstract}

Keywords New energy vehicle $\cdot$ Traction motor · Motor control · Power electronics converter · Control algorithm · Permanent magnet synchronous motor $\cdot$ Electric motor $\cdot$ Electric powertrain

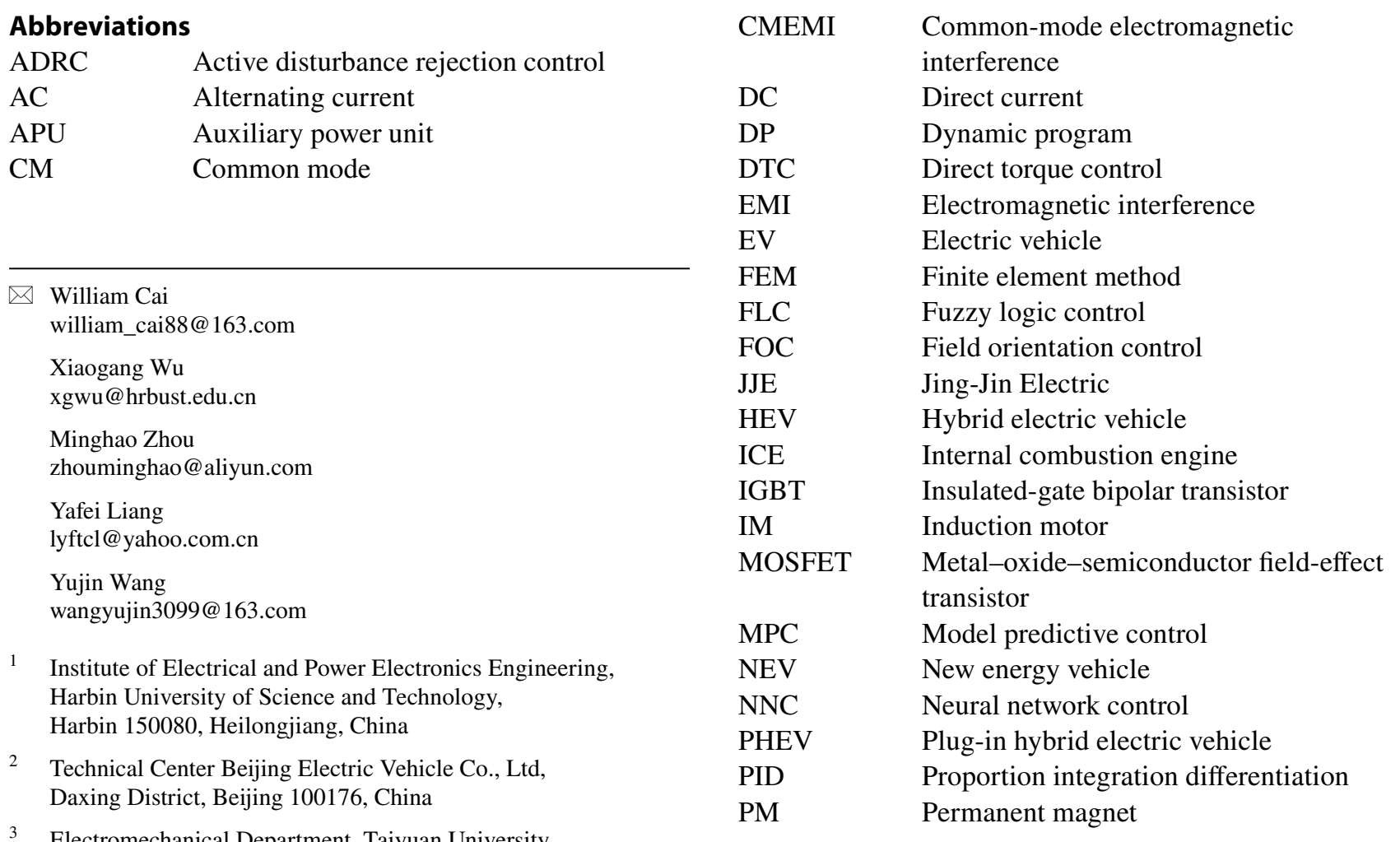




$\begin{array}{ll}\text { PM-BLDCM } & \begin{array}{l}\text { Permanent magnet brushless direct current } \\ \text { motor }\end{array} \\ \text { PM-HEM } & \text { Permanent magnet hybrid excitation motor } \\ \text { PMDCM } & \text { Permanent magnet direct current motor } \\ \text { PMM } & \text { Permanent magnet motor } \\ \text { PMSM } & \text { Permanent magnet synchronous motor } \\ \text { RC } & \text { Robust control } \\ \text { SMC } & \text { Sliding mode control } \\ \text { SOH } & \text { State of health } \\ \text { SRM } & \text { Switched reluctance motor } \\ \text { SPWM } & \text { Sinusoidal pulse width modulation } \\ \text { SSV } & \text { Six-step voltage } \\ \text { SVPWM } & \text { Space vector pulse width modulation } \\ \text { V/F } & \text { Voltage per frequency } \\ \text { WBG } & \text { Wide bandgap } \\ \text { WLTC } & \text { Worldwide light-duty test cycle }\end{array}$

\section{Introduction}

With the thriving economy, car demand has increased. However, fuel-powered vehicles emit carbon dioxide and nitrogen oxide, causing greenhouse effect on the climate and toxic effect on human health [1,2]. Moreover, a large amount of diesel consumption has caused the global energy crisis. According to statistical data, the increase of twothirds of the petroleum consumption comes from transportation industries, which is extremely unfavorable to the sustainable development of human society [3, 4]. Driven by the global emission reduction targets in the Paris Climate Agreement, new energy vehicles (NEVs) have become an important development direction of the automotive industry $[5,6]$. While European countries and their car manufacturers have scheduled to limit sales of the fuel vehicle, the NEV Industry Development Plan (2021-2035) has been promulgated by the Chinese government, in which the goals are set for the next 15 years. According to the statistics of the China Association of Automobile Manufacturers (CAAM), the production and sales of NEVs in China reached 1.242 and 1.206 million units, respectively, in 2019[7], 1.366 and 1.367 million units, respectively, in 2020.

Compared with industry motors, NEV traction motors should be adapted for harsh operating environments. Their operation modes are frequently switched between motoring and generating. Frequent starting and stopping, high rate of acceleration/deceleration, high torque at low speed and high power at vehicle high-speed climbing, high power density, large highly efficient operating area, low vibration and noise, high reliability and high performance-to-price ratio are required by the automotive industry $[8,9]$. Traction motors and motor power electronic controllers are the core parts for converting the electromechanical energy in NEVs $[10,11]$.
The electric powertrain systems integrated gears, clutch, and other mechanical components with the traction motors and motor controllers are also an indispensable system part of NEVs. The vehicle structure and propulsion are simplified in the e-powertrain dramatically, whose topologies greatly influence the NEV performance [12].

Therefore, the requirements for the electric drive systems in NEVs mainly include the following aspects: (1) high torque density and good torque control capability for vehicle dynamic performance; (2) reliability and durability for the required vehicle safety and life; (3) high efficiency within operation spectrum $[13,14]$ and high performanceto-cost ratio for the energy economy and the users' capital investment.

The technologies of traction motors, their power electronic controllers, and electric powertrains are summarized. The advantages and disadvantages of existing technologies and their prospects and development are discussed, providing reference for the researchers and engineers in NEVs powertrain system areas.

\section{Development of NEV Traction Motors}

\subsection{Classification and Characteristics of NEV Traction Motor}

The traction motors in NEVs mainly include direct current motors (DCMs), induction motors (IMs), permanent magnet motors (PMMs), and switched reluctance motors (SRMs). Among them, PMM is divided into PM DC motor (PMDCM), PM synchronous motor (PMSM), PM brushless DC motor (PM-BLDCM) and PM hybrid excitation motor (PM-HEM) [15]. To reduce the dependence on PM materials, excitation synchronous motor is also installed onboard vehicles, as shown in Fig. 1.

\subsubsection{Direct Current Motor}

DCM is used as the traction motor in electric vehicles (EVs) from the late nineteenth century because of its simple speed regulation. However, low efficiency, large mass, and poor reliability due to brushes and commutators make DCMs no longer suitable for high-speed NEVs. They are used only in low-speed EVs, such as carts for logistic cargo moving inside plants, and shuttle bus in scenic areas.

\subsubsection{Switched Reluctance Motor}

The SRM stator and rotor are composed of silicon steel laminates, and a salient pole structure is adopted. There are no windings, slip rings or PMs on the rotor, and only simple concentrated windings are installed on the stator. The rotor 


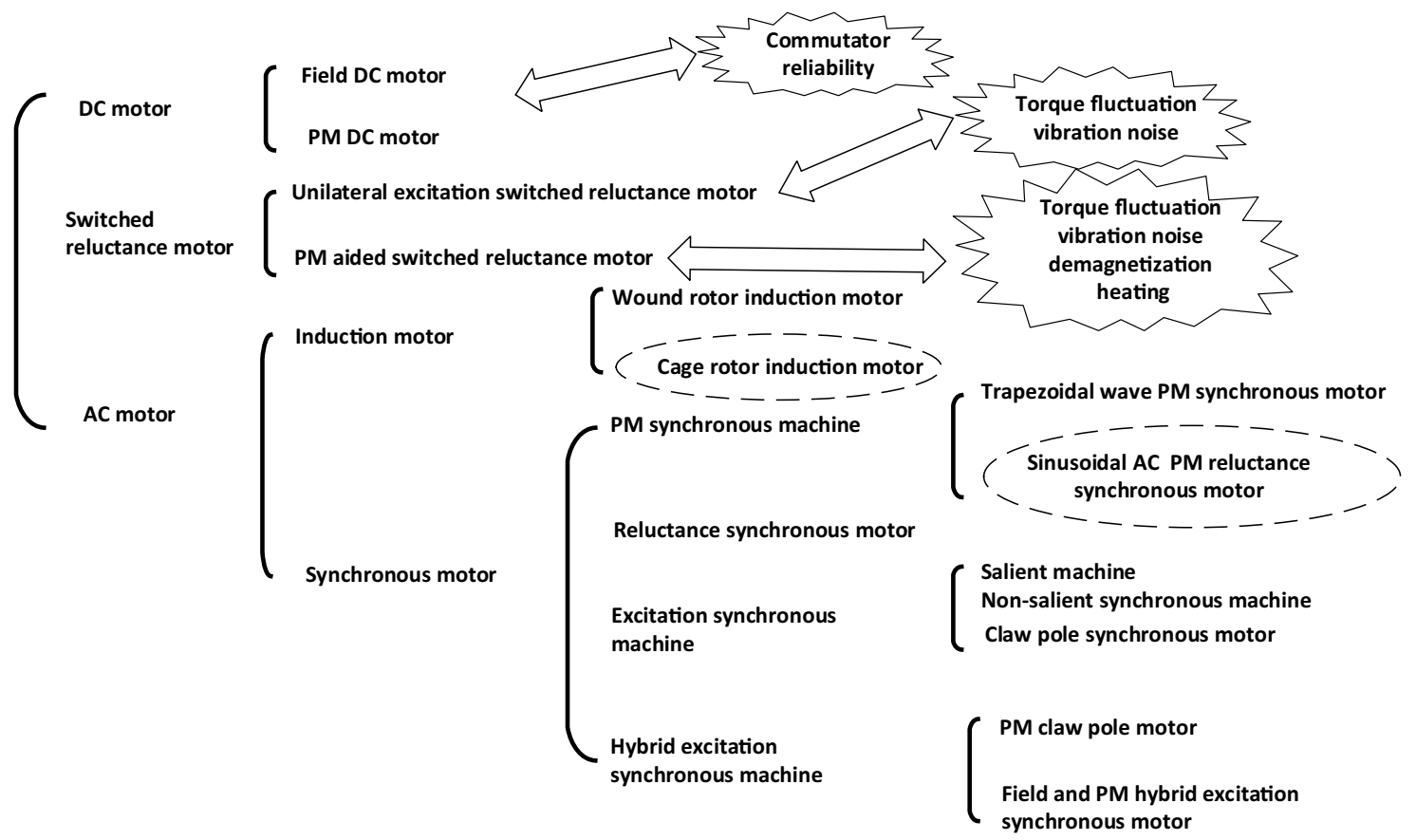

Fig. 1 Traction motors of NEVs

structure enables simple, robust, low cost, and high-speed operation of SRMs. Moreover, its inverter's reliable topological structure prevents it from short-circuit faults [16]. High efficiency and simple control are SRMs' advantages. However, torque fluctuation, noise, and vibration are serious preventing it from applications in NEVs.

\subsubsection{Induction Motor}

Squirrel-cage IMs are widely used in NEVs. Their stator and rotor are composed of laminated silicon steel sheets, and three-phase windings are inserted inside the stator lamination stack and aluminum or copper bars in the rotor slots with rings at both ends. IMs are characterized as having a simple and strong structure, low cost, high reliability, small torque ripple, low noise, and maintenance-free. IMs can be easily run at high speed over $15,000 \mathrm{rpm}$ with a wide constant power range. However, IMs control circuit is complex, and their efficiency and power density are relatively low compared to PMSMs, leading to its increasingly lower market share globally [17].

\subsubsection{Permanent Magnet Motor}

(1) Permanent magnet direct current motor
When field windings and magnetic poles of conventional DCMs are replaced with PMs, a PM-DCM is established. PM-DCMs show higher power density and efficiency, but it needs more maintenance and exhibits low life and torque fluctuation due to the commutator and brush system; these are still the concerns to be solved for EV applications.

\section{(2) Permanent magnet synchronous motor}

In PMSM, its stator with three-phase windings is the same or similar to IM or synchronous motor stator, and PMs replace the excitation winding of traditional synchronous motors. According to the position of PMs on or in the rotor, PMSMs can be divided into surface-mounted PMSM (SPM) and interior embedded type (IPM). Well-designed IPMs are featured by high reluctance torque, high efficiency, high power factor, low heat, simple structure, small package and low noise. With the development of power electronics control strategy, IPMs have become dominant in traction motor applications. In addition, owing to the fully enclosed structure, IPMs, being maintenance-free, show low wind friction losses and low windy noise.

(3) Permanent magnet brushless DC motor

PM-BLDCM is a special PMSM structurally and theoretically, but its windings are concentrated normally and the stator current waveshape is trapezoidal, instead of sinusoidal 
Table 1 Comparison of NEV traction motors

\begin{tabular}{|c|c|c|c|c|}
\hline Index & $\mathrm{DCM}$ & IM & IPM & SRM \\
\hline Efficiency & 0 & 0 & 00 & 0 \\
\hline Speed & 0 & 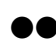 & 0 & 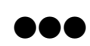 \\
\hline Size & 0 & & & \\
\hline Reliability & 0 & & & \\
\hline Control simplicity & & & 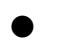 & \\
\hline Performance & 0 & & & \\
\hline
\end{tabular}

in SPM. The commutator-brush system is not required. However, the torque ripple and noise appear during electrical commutation, and it is difficult to achieve the maximum speed beyond twice the base speed.

\section{(4) Permanent magnet hybrid excitation motor}

By adding excitation windings to PMSM, the motor has both PMs and excitation windings and becomes a hybrid excited motor, which is PM-HEM. This motor has the minimum flux leakage, high flux density in the air gap, high power density, and good torque-speed characteristics. However, its topology and control are relatively complex owing to two separate excitations.

The performance comparison of the aforementioned motors is shown in Table 1.

In Table 1, $, 00,000$ represents the low (poor), medium, and high (good) indices, respectively. Thus, PMSM, especially IPM, is the best choice for NEV traction motors [18].

\subsection{Research of NEVs PMSM}

A new type of DC saturated hybrid excitation motors was proposed in Ref. [19]. By introducing additional DC field excitation with step-down DC saturation capability, the magneto resistive effect was constructed in the rear pole Vernier PMM (CP-VPMM). In this topology, the bidirectional flux control of the stator DC excitation reluctance motor and the good torque density in CP-VPMM are combined. An airgap-harmonic-oriented design method was proposed [20]. The magnetic flux enhancement was adopted, and its characteristics was $L_{\mathrm{d}}>L_{\mathrm{q}}$, which could be used in sensorless motor controls. By integrating a special design of stator teeth, the air gap length on the q-axis was increased to obtain high reluctance torque, good fault tolerance, and high reliability. Next, a hybrid circuit method to improve the efficiency of wound synchronous traction motors was proposed [21]. By changing the connection between windings $U, V, W$ and windings $X, Y, Z$, the efficiency at high speed could be improved. The torque ripples and the coupling between the internal/external magnetic fields of a compound excitation
PMM are reduced through finite element analysis in Ref. [22].

For the PMSM with a complex structure of double saliency, dual stators, and dual air gaps [23], a multiple sensitive objective optimization method was used to select the key dimensional parameters. Furthermore, the optimized geometrical dimensions were obtained by the response surface optimization method. Next, a six-phase fractional slot concentrated winding PMSM with fault tolerance capability was discussed [24]. Based on the analysis of magnet electromotive force harmonics, a new pole-slot matching scheme was proposed to reduce the eddy current loss of PMs caused by the concentrated windings and to reduce the number of rotor poles, and consequently the stator core losses.

\subsection{Development of the PMSM Technology}

The future technologies of traction motors for NEVs focus on the key factors of high efficiency, high speed, high power density, low vibration and noise, better electromagnetic compatibility (EMC) and low cost. In the EV development 2025 roadmap proposed by the US Department of Energy, the EV motors are aimed at achieving high efficiency (97\%), high power density $(50 \mathrm{~kW} / \mathrm{L})$, and low cost $(3.3 \$ / \mathrm{kW})$. In the "Energy-saving and New Energy Vehicle Technology Roadmap 2.0", the goals for 2025 are set as a specific power (power-to-mass ratio) of $5.0 \mathrm{~kW} / \mathrm{kg}$, power density (powerto-volume ratio) of $35 \mathrm{~kW} / \mathrm{L}$, and the peak efficiency of $97 \%$ for traction motors. To achieve these goals, global NEV traction motor suppliers and research institutions are collaborating to improve innovation chain and supplier chain, including components and materials.

\subsubsection{High Slot Filled Ratio Winding Technologies}

By adopting high slot filled ratio windings with flat/rectangular wires or hairpin windings [25], the winding heating can be greatly reduced, and the utilization rate of the winding copper materials can be increased by $15 \%-20 \%$, which is the main method to improve torque density, power density, and efficiency. For example, the power density of $4.6 \mathrm{~kW} / \mathrm{kg}$ is achieved in GM VOLT motor through hairpin wingdings.

\subsubsection{High-Speed Motor Technology}

The motor size is proportional to its torque. For a motor with given power requirement, its power equals torque multiplied by speed. By increasing the operation speed, the torque requirement for the motor can be reduced, thereby reducing the motor volume and weight, and its power density increased with the speed. For example, the traction motor speed of $17,900 \mathrm{r} / \mathrm{min}$ is used in Tesla Model 3, and the 
Table 2 Indicators of typical traction motors for passenger EVs

\begin{tabular}{lllll}
\hline Technical indicators & A brand in China & $\begin{array}{l}\text { GM } \\
\text { Bolt }\end{array}$ & Germany Bosch & $\begin{array}{l}\text { Tesla } \\
\text { Model 3 }\end{array}$ \\
\hline Peak power $(\mathrm{kW})$ & 130 & 130 & 150 & 165 \\
Max. speed $(\mathrm{r} / \mathrm{min})$ & 13,200 & 8810 & 16,000 & 17,900 \\
Peak torque $(\mathrm{N} \cdot \mathrm{m})$ & 315 & 360 & 310 & 416 \\
Peak efficiency (\%) & 97 & 97 & 97 & 97 \\
Power density (kW/kg) & 4.56 & 4.60 & 4.40 & 4.50 \\
Cooling method & Oil & Water & Water & Water \\
\hline
\end{tabular}

motor speed of $25,000 \mathrm{rpm}$ is aimed to be achieved by 2035 in NEV Technology Roadmap 2.0 of China.

\subsubsection{Efficient Thermal Management Technologies}

Soil cooling, oil and water combined cooling, and new cooling topologies are used to improve cooling technologies and heat transferring of traction motors, and the power density of the motors is raised consequently.

PMSMs for NEVs have made continuous progress globally in power density, system integration, efficiency, maximum working speed, winding manufacturing process, and cooling technologies. The technical indicators of typical motor products are shown in Table 2.

\section{Research of NEV Motor Control}

Nowadays, PMSM requires its control strategies to have fast system dynamic response, high dynamic/static precision, and strong anti-interference ability. However, the PMSM models are nonlinear; with strong coupling, time-varying parameters, multiple variables, and large disturbance, its control algorithms are complex. Therefore, the performance of the motors is affected directly by the control strategies. Typical control strategies include constant voltage/frequency ratio, classical proportion integration differentiation (PID), field-oriented approach, direct torque, sliding mode variable structure, adaptive and intelligent controls.

\subsection{Motor Control Technologies}

Among the PMSM control technologies, the variablevoltage-variable-frequency (VVVF) control method has absolute advantages in performance through the following three methods: the constant voltages-per-frequency (i.e., $V / F=$ const) control which is open-loop type and is based on the steady-state motor models, the field-orientation control (FOC) and direct torque control (DTC). The latter two are close-loop types and are based on dynamic motor models. The comparison of the three motor control methods is presented in Table 3.

\subsubsection{Constant V/F Ratio Control}

Constant $V / F$ ratio control, also known as constant flux control, can obtain the constant flux by guaranteeing that the stator voltage per frequency maintains constant. The state feedback control was adopted in an N-T coordinate system, and a new sensorless $V / F$ control method for PMSMs was proposed [26]. When the motor was running at low speed, the $T$-axis current is used to keep the system at high stability. To operate the motor stable at medium and high frequencies, a velocity stability loop is added, and an active power disturbance component is extracted for compensation [27].

$V / F$ control is a relatively common method for IMs' speed control with the advantages of simplicity, effectiveness, and high robustness to parameter variation. However, since it is an open-loop control, the control accuracy, dynamic response, and load capacity of the systems are reduced due to drifts of speed and flux in the $V / F$ open-loop control,
Table 3 Performance comparison of the three motor control technologies

\begin{tabular}{llllll}
\hline Control technology & $\begin{array}{l}\text { Structural } \\
\text { complex- } \\
\text { ity }\end{array}$ & $\begin{array}{l}\text { Robustness to } \\
\text { parameters pertur- } \\
\text { bation }\end{array}$ & Starting performance & Torque ripple & Speed range \\
\hline V/F control & Simple & Low & Rough & High & Narrow \\
FOC & Complex & High & Smoothly & High & Wide \\
DTC & Complex & High & Smoothly & Relatively high Wide \\
\hline
\end{tabular}


which leads to poor startup capability, high torque ripple, and narrow speed range. Therefore, $V / F$ controls are seldom used in vehicular traction motor control.

\subsubsection{FOC}

FOC was proposed by Blaschke in the 1970s. The stator current was decoupled into the torque component and magnetized under the constant rotor flux in the special dq0 coordinate system, and the control of alternating current (AC) motors can be equivalent to that of an unexcited DC motor. FOC can achieve smooth starting, low torque ripple and wide speed range, suitable for high dynamic response of machinery under tough working conditions.

A vector control strategy is proposed based on the motor speed-torque-current diagram [28]. The power demand and the energy consumption were effectively reduced, and the vehicle driving range was extended. A flux-weakening control strategy was proposed through an estimator with improved uncertainty and disturbance. A flux-weakening adjusting factor to smooth the torque ripple at motor corner speed is introduced [29]. The robustness at the flux-weakening area is enhanced consequently.

Setting up a motor dynamic model in the two-phase rotating coordinate is the key to a successful FOC, laying basis for high dynamic response under harsh working conditions.

\subsubsection{DTC}

The DTC was proposed by Depenbrock, with the current loop in the FOC system being removed and no complex coordinate transformation required. The two-bit bangbang control is used to generate PWM modulation signals in a two-phase static coordinate. DTC has the advantages of simple structure, fast dynamic response, low sensitivity to parameter perturbation, and strong robustness, therefore suitable for applications requiring rapid dynamic response and wide speed regulation. However, it also has the disadvantages of the current and torque ripples at low speeds and the requirement for high sample frequency. Many scholars combine the space vector pulse width modulation (SVPWM) and DTC to reduce these ripples.
An improved control strategy using the quadratic estimation method (QEM) and the harmonic voltage elimination (HVEM) methods was proposed [30]. The final voltage vector suppressing harmonic current of the stator was obtained; thus, the fast dynamic response and good steady performance were kept unchanged. A novel multi-machine robust DTC scheme based on the nonlinear model prediction (NMP) method was proposed [31]. It achieved the acceleration slip regulation (ASR) and anti-lock braking system (ABS) functions of four wheels PMSMs and better driving performance and vehicle stability. A fuzzy model predictive DTC (FMP-DTC) strategy for an IPM of EV is proposed [32]. The weighting factor adjustment was no more required for optimal switch state selection. The instantaneous torque response, small torque ripple, and accurate speed tracking were achieved. A voltage vector allocation strategy based on a dual-space vector PWM control scheme was proposed [33]. By selecting the most appropriate mode, the switching frequencies of the two inverters could be balanced and reduced, and the power-sharing in the maximum range could be obtained.

DTC control, even though simple, has an excellent dynamic and static performance. However, it has a limitation on the increase of inverter switching frequency. There is no current loop and the current protection should be done directly, so additional measurements to limit currents are needed. The "dead-time effect" is also obvious at low speed, and the change of stator resistance will distort stator current and flux linkage.

\subsection{Current Control Strategies (CCS)}

The strategies of PM control include $i_{\mathrm{d}}=0$, maximum torque per ampere (MTPA), maximum torque per volt (MTPV), flux weakening $(\mathrm{FWC})$, unit power factor $(\cos \Phi=1)$ controls. The performance comparison of these current control strategies is shown in Table 4.

\subsection{1 $i_{\mathrm{d}}=0$ Controls}

The advantages of this control strategy are algorithm simplicity, small computations, and no demagnetization effect,
Table 4 Performance comparison of current control strategies

\begin{tabular}{lllllll}
\hline $\begin{array}{l}\text { Current con- } \\
\text { trol strategy }\end{array}$ & $\begin{array}{l}\text { Complexity of } \\
\text { the algorithm }\end{array}$ & $\begin{array}{l}\text { Maximum } \\
\text { torque capac- } \\
\text { ity }\end{array}$ & Speed range & Robustness & Efficiency & Power factor \\
\hline$i_{\mathrm{d}}=0$ & Simple & Small & General wide & High & Low & Low \\
MTPA & Complex & Large & Wide & Low & High & General high \\
MTPV & Complex & Large & Wide & Low & High & General high \\
FWC & Complex & Small & Wide & Low & High & General high \\
$\cos \Phi=1$ & Simple & Small & Wide & High & High & High \\
\hline
\end{tabular}


which is generally applicable in low-power servo systems. However, its power factor is low. For the interior PMSM, this method does not utilize the reluctance torque of the motor, which reduces the motor torque performance. Thus, it is only used in surface-mounted PM motors (SPM).

\subsubsection{MTPA Controls}

MTPA strategy makes full use of the reluctance torque of motor, so the maximum torque output is greatly improved. With the same output torque, the stator current of this method is minimum, which reduces copper losses and improves efficiency. However, this control strategy is complex and the parameter robustness is not very high.

\subsubsection{MTPV Controls}

MTPVs make full use of the voltage limit ellipse and DC bus voltage. The high inverter capacity, the maximum output torque at flux weakening range and the quick system response can be achieved by this method. However, this control algorithm is relatively complex.

\subsubsection{FW Controls (FWC)}

In this method, the flux of the PM motor is reduced by increasing the $\mathrm{d}$-axis demagnetization current, which guarantees the voltage balance and improves the speed adjusting range. However, this control strategy is sensitive to motor parameter perturbations, which leads to low robustness.

\subsection{5 $\cos \Phi=1$ controls}

The unit power factor control based on $\cos \Phi=1$ makes the power factor equal to 1 by controlling the $d$-axis and $q$-axis currents of PMSM simultaneously without reactive power output. This control strategy makes full use of the motor inverter capacity, but its maximum motor torque capacity is reduced.

\subsection{Control Algorithms}

Besides PID control, many other advanced control algorithms are introduced. The comparison of several control methods is shown in Table 5.

\subsubsection{PID Control}

The classic PID control method is stable, reliable, conveniently adjustable, and simply structured, making a good method for linear and stationary objects. However, PMSM is a strong-coupling and nonlinear object, where the parameters change and interact complexly. To improve the motor speed regulation performance, PID control is combined with other control methods, such as adaptive PI, neural network PI, and fuzzy PI controls. However, in terms of motor torque tracking accuracy, response speed, torque ripple suppression, and parameter robustness, the algorithms above are not efficient for achieving excellent dynamic and static performance. Therefore, several other advanced control algorithms are proposed.

\subsubsection{Adaptive Control}

The adaptive control algorithm handles system uncertainties by adjusting the controller parameters online, thus having strong robustness. Among them, model reference adaptive control is the most common. Its system is composed of a reference model, an adjustable system, and an adaptive mechanism. However, the design of the reference model and adjustable system relies on the precise motor model, which is seriously influenced by the motor parameter perturbations.

\subsection{3 $\mathrm{H}_{\infty}$ Control}

As a typical robust control (RC) method, the $\mathrm{H}_{\infty}$ control algorithm aims at minimizing the sensitivity of the controller uncertainties to maintain the system control performance. Its

Table 5 Comparison of control methods

\begin{tabular}{|c|c|c|}
\hline Control method & Advantages & Disadvantages \\
\hline PID & Simplicity, easy to speed, strong applicability & Long response time, poor steady-state performance \\
\hline Adaptive control & Parameter self-correction, strong robustness & $\begin{array}{l}\text { Strong dependency on model accuracy, weak dynamic } \\
\text { performance }\end{array}$ \\
\hline Ho control & Strong robustness, disturbance resistance & Complicated solution process \\
\hline ADRC & Smooth response, strong disturbance resistance & Delay in the approximation process, multiple parameters \\
\hline MPC & Simple design, fast dynamic response & Complexity, strong dependency of model accuracy \\
\hline $\mathrm{NNC}$ & Convenient parameter setting, strong self-learning ability & Slow convergence, oscillations \\
\hline FLC & Simple design, model independence, high fault tolerance & Low systematism of fuzzy rule design \\
\hline SMC & Simple structure, easy to design, high robustness & Singularity, chattering phenomena \\
\hline
\end{tabular}


robustness and disturbance rejection are both strong, but the solution process is complex.

\subsubsection{Active Disturbance Rejection Control (ADRC)}

ADRC uses a disturbance observer to estimate the system uncertainties and then introduces the disturbance rejection into the control signals to compensate the uncertainties. ADRC provides a strong disturbance rejection. However, its observer's design parameters are numerous, the approximation process is delayed, and a certain steady-state error exists, which affects the motor control accuracy.

\subsubsection{Model Predictive Control (MPC)}

MPC is simple in design and has a fast dynamic response. Its action is based on solving an optimal control problem of open loop in the finite-time domain at every sampling moment. However, this control algorithm is complicated and depends on the motor model parameters.

\subsubsection{Neural Network Control (NNC)}

The NNC method can achieve a smooth start, small torque ripple, wide speed range, and high robustness with a simple parameter setting, strong self-learning ability, and low motor parameter sensitivity. However, the NNC structure is relatively complex, and online iterative computation leads to poor real-time performance. Thus, it is more suitable for off-line parameter identification.

\subsubsection{Fuzzy Logic Control (FLC)}

FLC has a simple structure, good robustness, and a small impact on the motor startup. It is well applied in the design of the AC servo motor control system. However, in practical applications, its design relies on experience and expert knowledge.

\subsubsection{Sliding Mode Control (SMC)}

The SMC algorithm, being invariable to external disturbances, has a simple structure, low sensitivity to the internal parameter perturbations, and high control accuracy. It is suitable for the control of nonlinear uncertain systems, but has a high torque ripple. Chattering, singularity, and mismatched uncertainty limit its applications. Advanced SMC algorithms were proposed to suppress the chattering and even eliminate it by reducing the switching gain and frequency and by smoothing the control signals.

Collaborative optimization for axial flux PMSM control system was proposed [34]. Fuzzy control improved the torque ripple, and SMC improved the motor dynamic performance, effectively enhancing the range and acceleration performance of EVs. A variable SMC controller based on a speed loop was proposed [35]. It combined MTPA to control the IPM and obtained significant control reliability and flux-weakening performance.

\subsection{PWM Control}

Among numerous PWM methods, space vector pulse width modulation (SVPWM), sinusoidal pulse width modulation (SPWM), and six-step voltage (SSV) are the most common. Their performance comparison is shown in Table 6. For the given DC bus input voltage and the phase output current capability, high DC bus voltage utilization can help the motor output more power at and after the corner speed (i.e., to the flux-weakening range).

\subsubsection{SVPWM}

SVPWM enables the motor to obtain a circular magnetic field with constant amplitude. Compared with SPWM, $15.47 \%$ higher DC bus voltage utilization can be achieved, which allows more power to be outputted at high-speed operation. Low current waveform distortion or a small account of current harmonic components can also be achieved. Furthermore, the rotating magnetic field is closer to the circle, which greatly improves the motor performance. Thus, SVPWM is the dominant modulation in motor control.

\subsubsection{SPWM}

SPWM focuses on solving the problem of three-phase symmetrical sinusoidal voltage frequency and voltage regulation from the standpoint of the motor power supply. However, its total harmonic distortion is larger than that in SVPWM, which impacts negatively the control performance. More severely, the amplitude of its fundamental phase voltage can only be $1 / 2$ of the DC bus voltage, which may only be used in the low-speed range before the corner speed.

Table 6 Performance comparison of modulation methods

\begin{tabular}{lllll}
\hline $\begin{array}{l}\text { Modulation } \\
\text { method }\end{array}$ & $\begin{array}{l}\text { Structural } \\
\text { complex- } \\
\text { ity }\end{array}$ & $\begin{array}{l}\text { Harmonic } \\
\text { compo- } \\
\text { nent }\end{array}$ & Torque ripple & Robustness \\
\hline SVPWM & Complex & Low & Low & High \\
SPWM & Simple & High & High & Low \\
SSV & Simple & High & High & Low \\
\hline
\end{tabular}




\subsubsection{SSV}

SSV can adjust the power by controlling the voltage amplitude, flux, and torque, which can provide the highest DC bus voltage utilization ratio, thus beneficial to a greater power output at speeds beyond the motor corner speed. However, its harmonics are rich in the phase current and in the airgap magnetic field, leading to the fifth- and seventh-order harmonics with higher amplitude.

\subsection{Power Electronic Devices in Control}

The new generation of insulated-gate bipolar transistor (IGBT) chips for NEVs were launched by international component suppliers like Infineon, Fuji, Mitsubishi, and Renesas. For example, Infineon IGBTs are based on an 8-in. or a 12-in. technology platform, while IGBTs are manufactured on a 6-in. or an 8-in. wafer in China. Nevertheless, there are still some gaps in the device performance indicators, key process technology, production quality control, and cost. The IGBT module packaging with vehicle standard (equivalent to imported modules like HP1, HP2, and HP Drive) is close to the international average level in performance and reliability, and their large-scale application in automotive just begin in China.

Compared with traditional silicon devices, wide bandgap (WBG) power devices represented by $\mathrm{SiC}$ and $\mathrm{GaN}$ show strong advantages in voltage, operating temperature, switching frequency, and switching losses, which makes them more suitable for NEV inverter requiring tolerance to high temperature, high voltage, high frequency, and high power density [35]. The material property comparison among $\mathrm{Si}, \mathrm{SiC}$, and $\mathrm{GaN}$ is shown in Fig. 2 [36].

WBG device applications are explored in electrical drive systems. When the motor controller's power density exceeds

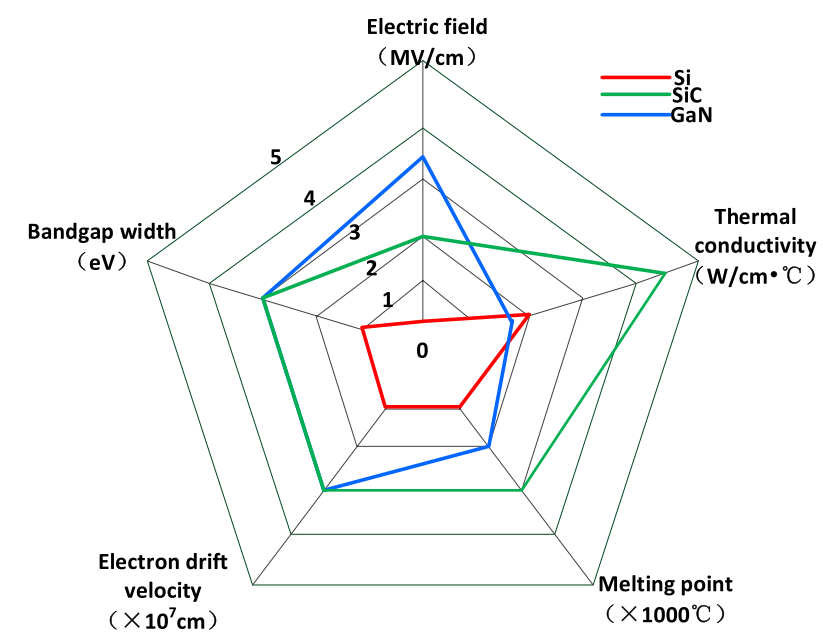

Fig. 2 Property comparison of $\mathrm{SiC}, \mathrm{Si}$, and $\mathrm{GaN}$
$25 \mathrm{~kW} / \mathrm{L}$, the WBG semiconductor can be used for heating reduction due to low conduction loss at a high-frequency switching operation [37]. A buck converter prototype with a $\mathrm{SiC}$ power module was established for continuous operation at high-temperature operation [38]. The $\mathrm{SiC}$ module's high performance could still be found at its junction temperature of $225^{\circ} \mathrm{C}$. An integrated low-voltage rating of the $\mathrm{GaN}$ module was used to set up a three-phase full bridge inverter, resulting in the reduction in not only the inverter weight and volume but also the device resistance and conduction loss [39]. However, if the WBG device switching frequency was increased to $50-100 \mathrm{kHz}$, the EMC influence caused by its high $\mathrm{d} v / \mathrm{d} t$ on the efficiency would be more prominent [40]. Electromagnetic interference (EMI) levels of $\mathrm{SiC}$ and $\mathrm{Si}$ devices with similar topology were compared under the same working conditions [41]. The results showed that the miller effect caused by the parasitic parameters in SiC JFET devices was the main reason of high EMI. An insulated metal substrate was installed on the division of the motor drive inverter with a SiC JFET for restraining the common mode (CM) and EMI [42]. It was shown that the third-order LCL filter had better performance than the fourth-order of LCL. Stray inductance between power electronics and the converter output was utilized as a filter, combined with an additional RC link, for a high-frequency 100-1 MW inverter with $\mathrm{SiC}$ [43]. The test showed that even for a measured value of $47 \mathrm{kV} / \mu \mathrm{s}$, the inverter output $\mathrm{d} v / \mathrm{d} t$ could be limited to $7.5 \mathrm{kV} / \mu \mathrm{s}$.

To handle the ground-drain current, $\mathrm{CM}$ electromagnetic interference (CMEMI) and bearing current in the motor inverter with WBG devices, a new concept of CM voltage cancelation through a balancing inverter topology and a double-winding stator structure was proposed [44]. In a test based on GaN, although the parasitic capacitance in the case of asymmetric windings limited the CM cancelation, the ground current amplitude could be reduced by $90 \%$, and the conduction CMEMI emission could be reduced by an average of $20 \mathrm{~dB}$ without using any filter. In Ref. [45], a standard driver circuit was adopted by adding a simple coupling circuit, to drive two series-connected $\mathrm{SiC}$ metal-oxide-semiconductor field-effect transistors (SiC MOSFETs), and a limiting buffer circuit was used for voltage balancing. It has the advantages of low cost, simple structure, and high reliability.

\subsection{Motor Controller Development}

High efficiency, high density, and good EMC performance are the development directions of motor controllers. By adopting power electronics integration technology, the weight and volume of the whole controller can be reduced effectively, power density can be increased, and manufacturing cost can be reduced. Power electronics integration 
Table 7 Comparison of power density of motor controllers

\begin{tabular}{llll}
\hline Items & Toyota Prius Gen4 & Bosch Gen3 & Conti. Gen3 \\
\hline Power density (kW/L) & 25.0 & 25.0 & 23.0 \\
Power ratio weight (kW/kg) & 23.2 & 22.8 & 21.0 \\
Peak power (kW) & 105 & 125 & 135 \\
DC voltage class (V) & $200-600$ & $300-450$ & $300-450$ \\
Device current (A) & $350 A r m s$ & 400 Arms & 450 Arms \\
Device package form & Custom & Custom & Custom \\
\hline
\end{tabular}

technology is mainly divided into three levels: monolithic integration, hybrid integration, and system integration. Hybrid integration schemes are mostly adopted in motor controllers such as Toyota Prius and GM Volt. Module packaging, interconnection, and efficient cooling are the core of power electronics hybrid integration. The comparison among global advanced products is shown in Table 7.

For SiC motor controllers, full use of the high-temperature tolerance, high efficiency, and high frequency of $\mathrm{SiC}$ MOSFET devices is the key to improving the power density and efficiency further. SiC MOSFET inverter was applied in Tesla Model 3, shown in Fig. 3b. Its SiC motor controller is composed of $24 \mathrm{SiC}$ MOSFET chips grouped in parallel and mounted on a pin-fin radiator to achieve high current output (800Arms). Through the laser welding process, each $\mathrm{SiC}$ MOSFET is connected to a copper busbar, which greatly improves the connection reliability. Full $\mathrm{SiC}$ inverters are launched for vehicle applications by other companies. It was found by Toyota that under load conditions, the loss of SiC power control unit (PCU) of the prototype vehicle was reduced by $30 \%$ compared with IGBT PCU in Fig. $3 \mathrm{f}$. Double-sided welding and double-sided cooling technology were adopted by Denso to achieve small size and high efficiency of its $\mathrm{SiC}$ controller in Fig. 3a, which was used in Toyota fuel cell vehicles.

Typical full SiC controllers are shown in Fig. 3.

SiC MOSFET controller was developed by Jing-Jin Electric (JJE) for VW commercial vehicles, whose power density is over $40 \mathrm{~kW} / \mathrm{L}$. The hairpin winding motor and $\mathrm{SiC}$ controller prototypes were developed for EU passenger car OEM by JJE at the end of 2019. In 2020, 300-600 kW series of SiC MOSFET inverters, shown in Fig. 3e, were developed by JJE for TRATON group, a VW commercial vehicle division. The $\mathrm{SiC}$ inverter, shown in Fig. 3c, is also embarked onboard of BYD EV-HAN in July 2020.

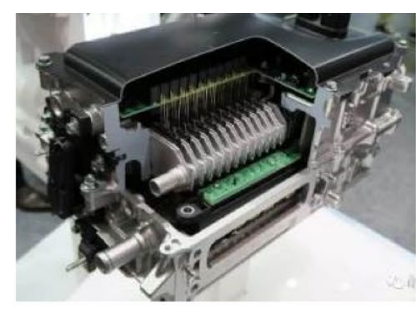

(a) Denso SiC controller

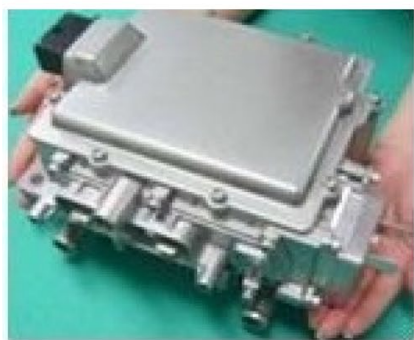

(d) Hitachi all-SiC controller

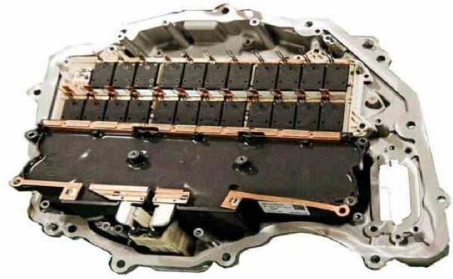

(b) Tesla SiC controller

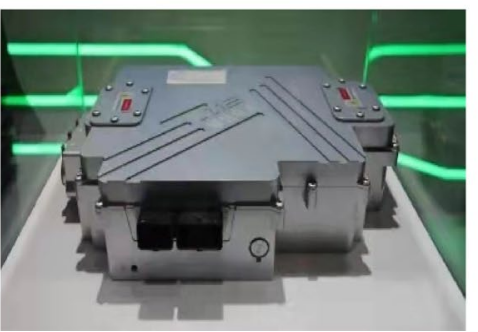

(e) JJE SiC controller

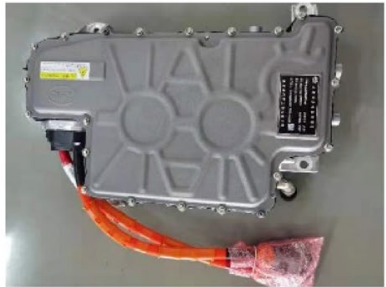

(c) BYD SiC controller

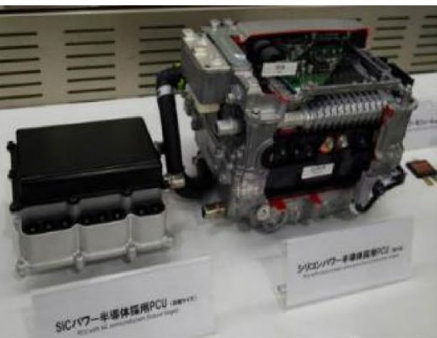

(f) Toyota full SiC PCU

Fig. 3 Typical SiC motor controllers 


\section{NEV Powertrain Development}

\subsection{BEV Powertrain Topology}

Battery EV (BEV) powertrain generally includes the motor, power electronics control system, and reducer or transmission. Its configuration depends mainly on the layout of the electric drive system inside the vehicle. Electric drive systems can be categorized into single-motor drive (or lump e-drive), distributed-motor drive, and range-extended drive systems [46].

\subsubsection{Single-Motor Drive System (or Lump e-Drive System)}

A single-motor drive system is similar to the scheme of traditional internal combustion engine (ICE) vehicles, but the electrical motor replaces the ICE, and other configurations are modified accordingly. However, this configuration has a large demand for chassis space.

A single-motor drive system can be mounted on the front or rear drives, and its reducer/transmission structures can be divided into three categories, as shown in Fig. 4.

An EV motor and a high-accuracy vehicle analysis model were proposed in Ref. [47]. The design space of the motor could be accurately described and the entire electric drive system was optimized. The influence of a non-deterministic modulation scheme on the transmission system was conducted based on the single IPM. The transmission mechanical part was modeled as a dual oscillator, and different inverter modulation schemes (hysteresis controller, PWM method) were applied. The inverter-generated harmonics and switching frequency were taken as the optimization targets. The simulation results showed that the pulse frequency could be reduced in the hysteresis controller. In addition, the inverter-generated partial harmonic energy could compensate for the filter absence. The IPM drive system with five-phase windings was comprehensively compared with IPM systems with three phases [48]. The proposed fivephase motor has the advantages of low cost, small torque ripple, high power density, good capability of flux weakening, strong fault tolerance, high reliability, and more design freedom.

\subsubsection{Distributed Electric Drive System}

Multiple motors are distributed to the corresponding vehicle wheels. According to the motor location, it can be categorized into three types: wheel rim, hub type, and combined, as shown in Fig. 5.

Connecting wheels directly to the motors can realize the precise measurement of the wheel torque and rapid response to the driving requirement. The vehicle chassis configuration

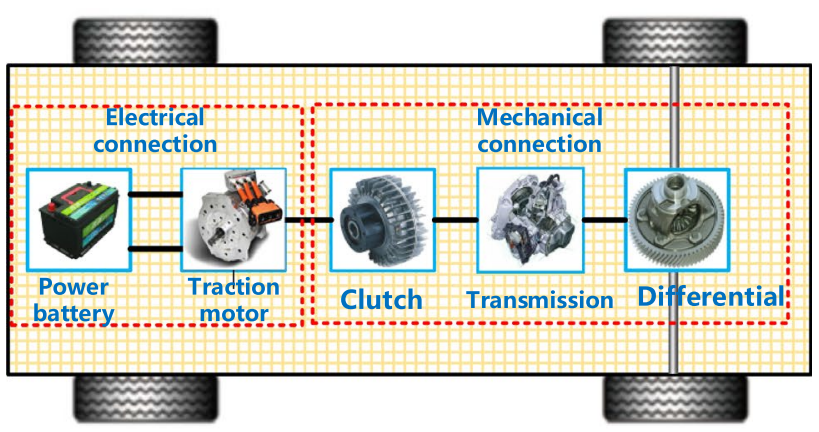

(a) Electric drive system with a clutch

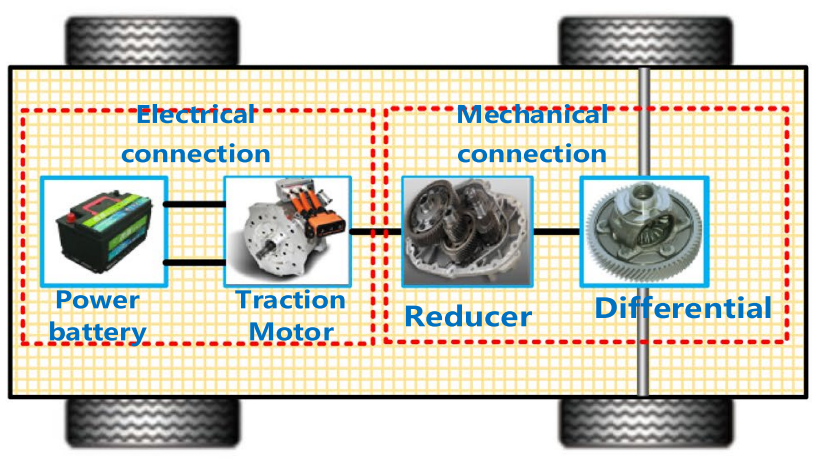

(b) Electric drive system without the clutch

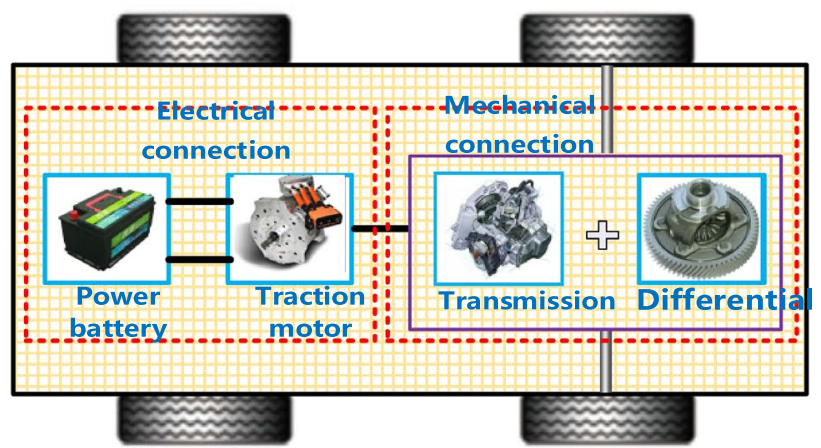

(c) Integrated electric drive system

Fig. 4 Single-motor electric drive systems

is simplified, the user available space is expanded, the vehicle weight and the energy consumption are reduced, and the driving range per charge is consequently increased. Therefore, the distributed motor drive system has been recognized as one of the most promising electrified propulsion systems. However, there is no mass production of vehicles with the 


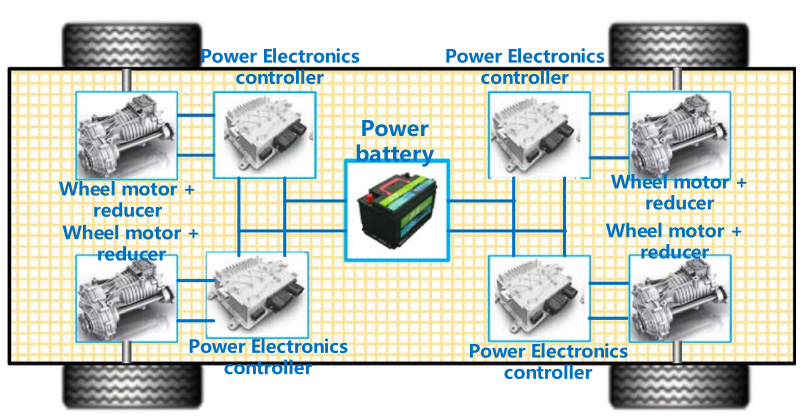

(a) Wheel side motor drive system

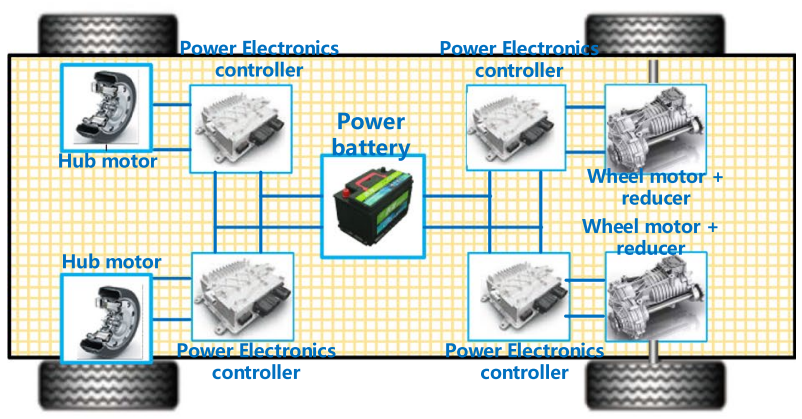

(b) Wheel rim-hub motor drive system

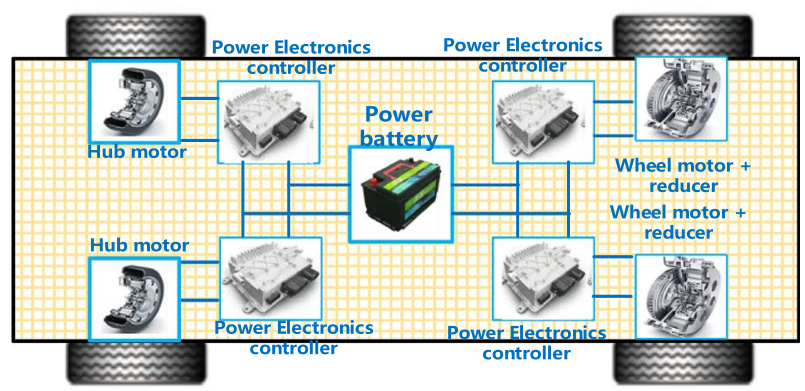

(c) Wheel hub motor drive system

Fig. 5 Distributed electric drive systems

distributed e-drive systems, except for the wheel side motor drive system used in BYD K9 buses. Now, the research mainly focuses on the control strategies such as torque distribution optimization [49, 50].

An algorithm for four-wheel distributed drive control was proposed for a fast, energy-saving, and easy-to-realize torque allocation [51]. The experimental results showed that the proposed algorithm was reasonable, and the system efficiency was improved significantly in the lateral acceleration range of the entire ramp. The particle swarm optimization algorithm was used for searching the optimal global size of four-wheel-driven EV [52]. The simulation results showed that the particle swarm optimization method combined with the real-time torque allocation strategy could effectively reduce the size of the main components of the powertrain and reduce energy consumption. Next, a hierarchical control strategy for a four-wheel distributed drive system was proposed to meet the driver's operating instructions and maintain the lateral stability of the vehicle [53]. The control strategy was divided into two layers. The upper layer realized nonlinear MPC, and the lower layer controlled the wheels through a PID controller. The experimental results showed that the driver's longitudinal and lateral motion commands were performed with a good real-time performance.

Hub motor for passenger vehicles has no global mass production owing to the constraints of cost, reliability, braking safety, and control. The mechanical, electrical, and thermal issues are not well solved. Only the samples or small demonstration prototypes could be seen in the market. As for commercial engineering vehicles like buses and heavyduty trucks, hub motors are already used owing to relatively unstrung layout space in wheels, low vehicle speed, relatively low sensitivity to unstrung mass increment, which provides low floor, and large space to bus passengers.

\subsubsection{Extended Range EV (EREV or REEV) System}

An augmented electric drive system differs from singlemotor and distributed motor drive systems because it contains an auxiliary power unit (APU). The system configuration is shown in Fig. 6, which is also classified as plug-in HEV (PHEV). A low-power engine is usually used. Compared with the battery drive system, the battery capacity here can be reduced appropriately, which has a good application prospect in mid-sized vehicles. However, this drive system has a high cost and needs support from ground chargers [54, 55].

The configuration and performance details of traction motors A and B in the electric drive system of Chevrolet EREV were introduced [56]. The simulation results showed that the bar-wound winding (hairpin winding) motor had better performance than that of the motors with the strand round wire windings. In addition, the rotor with cavitation at the magnet top was specially designed to improve the spin loss by reducing the flux density harmonics in the motor airgap. Owing to the advantages of the Volt electric drive system and control algorithm, its noise reduction was also significant. A multi-objective optimal energy management method was proposed for APU fuel consumption and battery state of health $(\mathrm{SOH})$ in extended-range electric buses [57]. The APU fuel consumption and battery $\mathrm{SOH}$ were used as optimization targets, and the dynamic program (DP) algorithm was used to solve the multi-objective problem. The simulation results showed that the optimal economic effect could be obtained if the battery pack parameters and the control strategy were set to the minimum without battery replacement. Furthermore, a novel energy management 


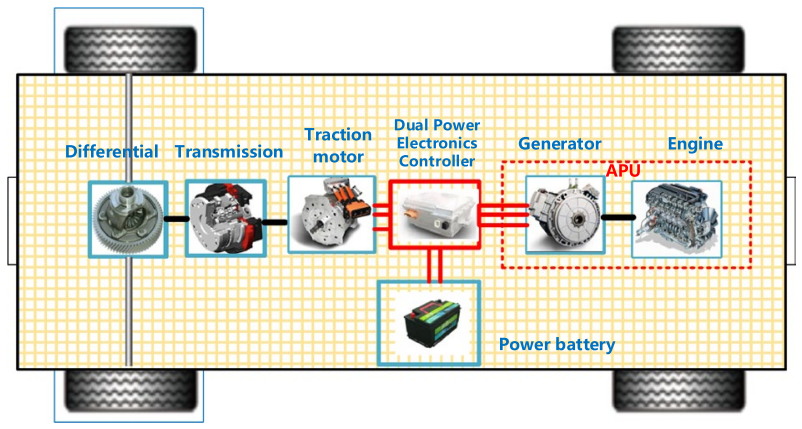

Fig. 6 EREV system

optimization strategy aiming at the APU configuration and control method in EREVs was proposed to solve the power distribution issue of APU and battery [58]. The model of the APU control system was established, and two strategies for APU power tracking were proposed according to different power change rates under the condition of changing APU dynamic response characteristics and control parameters. The experimental results showed that the APU power change rate under different conditions could significantly affect fuel consumption.

\subsection{Hybrid Powertrain}

An engine, electric motor(s), and power batteries are combined, and two power sources are matched and optimized for greatly reducing vehicle emissions and fossil energy consumption $[59,60]$. According to the combination of power sources, HEV powertrains can be classified into three types: serial, parallel, and series-parallel compound.

\subsubsection{Series Hybrid Powertrain}

The series hybrid power system is shown in Fig. 7. The engine and the motor are connected in series. The engine

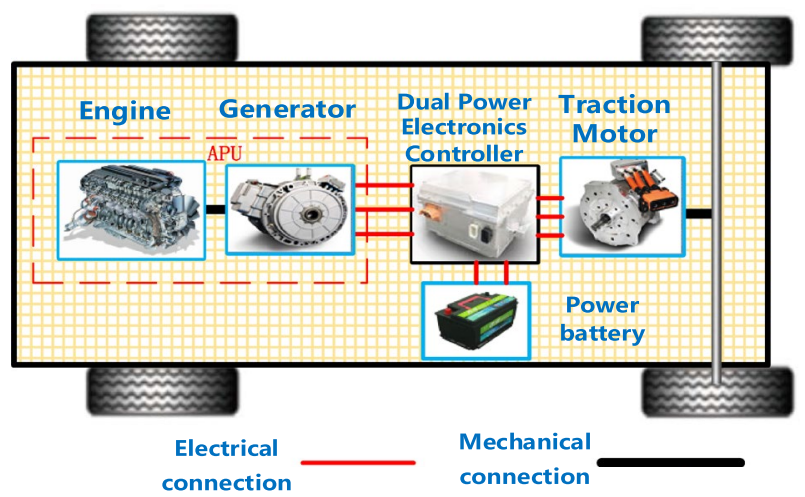

Fig. 7 Series hybrid power system does not propel wheels mechanically, and it only drives the generator to generate electricity through burning fuel. The generated electric power is sent to the traction motor, which creates the traction torque to drive the whole vehicle. Simultaneously, the power battery can also supply the electric power to the traction motor to operate the vehicle.

As only the traction motor drives the wheels, the engine is not affected by the driving conditions, which could be set for continuous operation at the most efficient point. However, the energy to drive the vehicle undergoes two conversions: mechanical to electrical and then to mechanical. Thus, the fuel energy utilization rate is relatively low.

In the study of serial hybrid powertrains, the combined optimization of an energy management strategy and driving speed was investigated for minimizing fuel consumption [61]. An energy management strategy based on the road condition and the driving time was proposed to find the optimal driving speed and energy power allocation for specified driving tasks. A power follower control strategy was combined with the DC side voltage control strategy, and a novel idea for energy management of hybrid EVs was proposed [62]. Experimental results showed that this series hybrid vehicle had better fuel economy than the single control scheme. Furthermore, a multi-function framework for hybrid powertrains considering the driving conditions was proposed [63]. Using a diesel-powered traditional vehicle as a hybrid target, a hybrid topology combining the series-connected hybrid and wheel-motor systems was presented. Compared with the traditional vehicles, the acceleration performance and the climbing gradient were improved by $18 \%$ and $10 \%$, respectively. For the PM generator in the series hybrid configuration, the hybrid excitation topology was proposed [64], together with the integrated passive rectifier, replacing the PMSM and the active power electronic converter, which facilitated the constant control of the PM flux linkage. This design was confirmed to provide higher output voltage and power density.

\subsubsection{Parallel Hybrid Powertrain}

The parallel hybrid power system is shown in Fig. 8. The engine and the motor shafts are connected in parallel. The vehicle can be driven by the engine and the motor together or by one of them alone. There is no dedicated generator in this configuration, and the power battery pack can only be charged by the traction motor operating in its generating mode. However, the engine working condition is often affected by the vehicle driving cycle, and it cannot always run at the optimal working point. Compared with the series hybrid power system, a more complicated transmission is required.

An energy management strategy model based on a deep recursive neural network was proposed for the optimal 


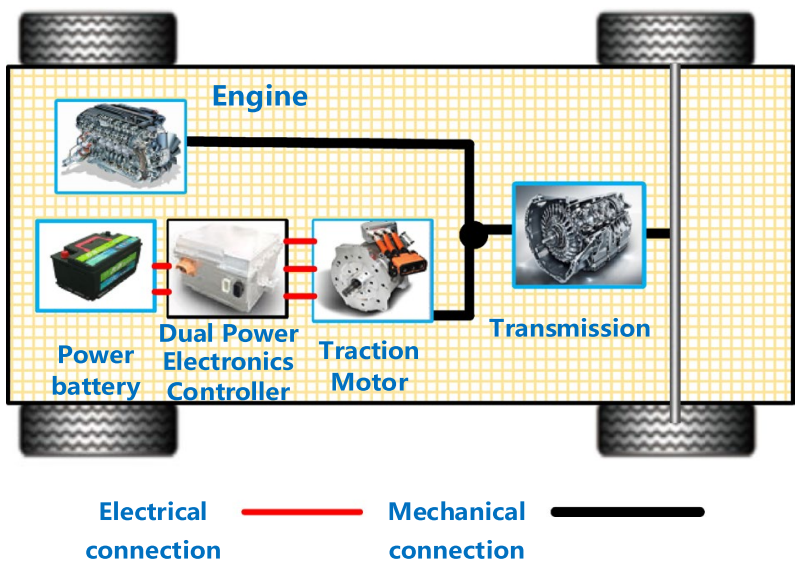

Fig. 8 Parallel hybrid power system

torque distribution of single-axle parallel hybrid vehicles [65]. Better performance in terms of fuel economy and accuracy was provided. Further, an adaptive neuro-fuzzy reasoning system was combined with the equivalent power consumption minimization strategy, and a practical adaptive energy management strategy for parallel hybrid buses was proposed [66]. The results showed that the fuel economy was improved by this control strategy. A torque balance threshold change strategy was proposed for the energy management of parallel hybrid vehicles [67]. When the engine was active, it runs at constant torque, to ensure its operation at highly efficient points. Further, an electro-hydraulic parallel hybrid powertrain for urban vehicles was introduced [68]. The power consumption and battery discharge stress of the electric powertrain were reduced by hydraulic system. The vehicle driving range per charge was increased, and the battery life was improved. Aiming at the mode conversion of parallel hybrid vehicles, a control method based on an adaptive double-loop control framework was proposed [69]. The experimental results showed that the proposed control method could effectively improve the performance of HEVs. In addition, the time of the mode conversion process was shortened and the vehicle turbulence within an acceptable range could be controlled.

\subsubsection{Series and Parallel Compound Powertrain}

In compound powertrains, the relationship between the generator and the motor can be either series or parallel, as shown in Fig. 9. The engine can directly output propulsion power through nodes $1,2,4$ to drive the vehicle together with the motor or to generate electric power through nodes 1 , 3 when only the motor drives the vehicle mechanically. Usually, when the vehicle is running at low speed, the driving system works mainly in series. When the vehicle is running stably at high speed, the main operation mode is parallel.
The optimal matching of all components to the greatest extent can be achieved and the contradiction between the fuel energy utilization rate and the engine's best working condition can be balanced with the compound hybrid system. Compared with the parallel configuration, this compound is more complex and has higher requirements on the power combination components.

The system efficiency was improved by optimizing the configuration, e.g., by adding gears to components or gearboxes with several transferring ratios [70]. To solve the working area mismatch between the engine and the motor, a new multi-mode coupling drive system was designed by coupling a distributed drive system with a centralized drive system and adding a clutch [71]. The results showed that the system efficiency was improved because the engine and motor operating points fall within their effective ranges. The optimal transferring ratio and motor size were determined based on the requirements for fuel economy, acceleration, and maximum speed performance [72]. The proposed method had the advantage of obtaining a more accurate compact EV powertrain. To solve the power allocation and management in the hybrid configuration, an energy management strategy based on nonlinear MPC was proposed [73]. Compared with the charge depletion strategy, the fuel economy was improved by $18.86 \%$ and $10.36 \%$, through the nonlinear MPC and equivalent power consumption minimization strategies, respectively. Aiming at the PMM performance optimization, the brushless dual-rotor motor with axial magnetic field modulation was investigated [74], which could be connected to the traditional PMSM, forming a dynamic composite device. The axial tilting moment was analyzed, and the necessary conditions to avoid the axial tilting moment were given.

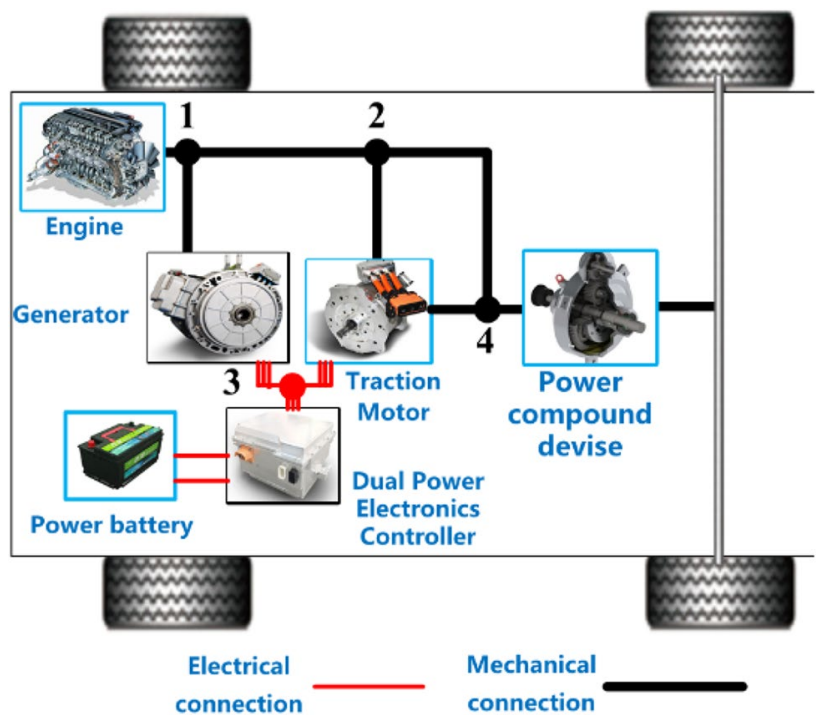

Fig. 9 Series and parallel compound powertrain 

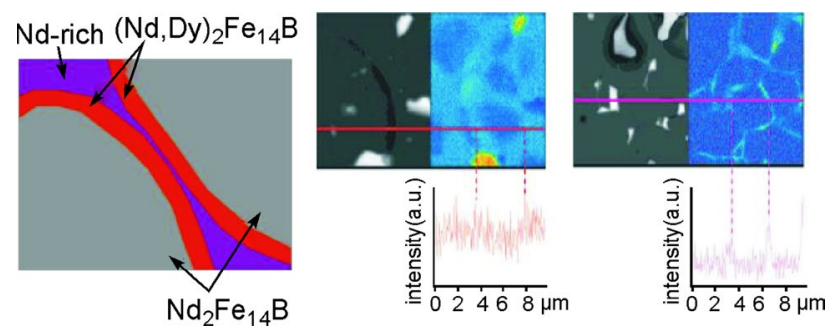

Fig. 11 Grain boundary diffusion and grain boundary modulation of the PM

to the APU's existence, the driving distance per charging is increased. However, a lot of space in the system is occupied by the transmission structures, and the working efficiency is not very high.

\subsubsection{Hybrid Powertrain Comparison}

The advantages and disadvantages of different hybrid powertrains are shown in Table 9.
The advantages of the series configuration are mainly reflected in the simple structure, relatively easy control, and optimal engine working point. The main parallel configuration advantages are good fuel economy and relatively simple structure. The series-parallel compound configuration combines the characteristics of both series and parallel configurations, so it can adapt to a variety of driving conditions. However, the system is complex and the control is difficult.

\section{Technical Innovation and Development Forecast of the NEV Electric Drive Systems}

The technical architecture of the NEV electric drive system is shown in Fig. 10. It mainly includes powertrains, core subassemblies, key materials, components, and basic support.

The innovation of the NEV electric drive system technology can be summarized as the overall improvement of the entire supplier chain technology from materials, parts/ components, and the motor systems to the powertrains.

Table 10 Objective parameters on the technical roadmap of electric drive systems

\begin{tabular}{|c|c|c|c|c|}
\hline Performance of powertrains, components, and materials & 2020 & 2025 & 2030 & 2035 \\
\hline Specific power of e-motors $(\mathrm{kW} / \mathrm{kg})$ & 4 & 5 & 6 & 7 \\
\hline Area percentage at the e-motor efficiency $\geq 80 \%$ & 88 & $90 \%$ & $93 \%$ & $95 \%$ \\
\hline E-motor cost $(¥ / \mathrm{kW})$ & 35 & 30 & 25 & 20 \\
\hline Power density of power electronics converters $(\mathrm{kW} / \mathrm{L})$ & 25 & 40 & 50 & 70 \\
\hline Area ratio of the converter efficiency $\geq 90 \%$ & $88.5 \%$ & $90 \%$ & $92 \%$ & $94 \%$ \\
\hline Power electronics converter cost $(¥ / \mathrm{kW})$ & 40 & 30 & 25 & 20 \\
\hline Specific power of EV e-powertrains $(\mathrm{kW} / \mathrm{kg})$ & $1.8-1.9$ & 2.0 & 2.4 & 3.0 \\
\hline Efficiency of EV e-powertrains under CLTC & $86 \%$ & $87 \%$ & $88.5 \%$ & $90 \%$ \\
\hline EV e-powertrain cost $(¥ / \mathrm{kW})$ & $75-80$ & 72 & 60 & 50 \\
\hline Mass reduction percentage of $\mathrm{HEV}$ powertrains & Base & $20 \%$ & $35 \%$ & $50 \%$ \\
\hline Efficiency of HEV powertrains under WLTC & $81 \%$ & $83 \%$ & $84 \%$ & $86 \%$ \\
\hline Torque density of direct drive hub motors $(\mathrm{Nm} / \mathrm{kg})$ & N/A & 20 & 24 & 30 \\
\hline Loss of silicon steel sheets (kW @P1.0/400, @P1.0/800 & 14,37 & 13,36 & 12,33 & 11,30 \\
\hline Magnetic polarization of silicon steel sheets $(\mathrm{T})$ & & 1.66 & 1.67 & 1.68 \\
\hline Remanence of PM martials (T) & 1.35 & 1.40 & 1.45 & 1.50 \\
\hline Coercive force of PM martials (kA/m) & 2300 & 2300 & 2400 & 2400 \\
\hline Percentage of heavy rare earth materials $(\mathrm{Dy}+\mathrm{Te})$ & $4 \%$ & $3 \%$ & $2 \%$ & $1 \%$ \\
\hline Corona guard life of flat enameled wires (h) & $100 @ 12 \mathrm{kHz}$ & $100 @ 20 \mathrm{kHz}$ & $100 @ 30$ kHz & $100 @ 50 \mathrm{kHz}$ \\
\hline Thermal tolerance temperature of insulation $\left({ }^{\circ} \mathrm{C}\right)$ & $180-200$ & 200 & 220 & 240 \\
\hline Thermal conductivity of insulation systems (W/mk) & $>0.25$ & 0.3 & 0.4 & 0.5 \\
\hline Limiting speed of bearings with $d \leq 35 \mathrm{~mm}(\mathrm{rpm})$ & 16,000 & 20,000 & 25,000 & 28,000 \\
\hline Fatigue life of bearings & & $5 \mathrm{~L} 10$ & $6 \mathrm{~L} 10$ & $8 \mathrm{~L} 10$ \\
\hline Current density of IGBT chips at $750 \mathrm{VDC}\left(\mathrm{A} / \mathrm{cm}^{2}\right)$ & 300 & 350 & 400 & 450 \\
\hline Current density of $\mathrm{SiC}$ chips at $1200 \mathrm{VDC}\left(\mathrm{A} / \mathrm{cm}^{2}\right)$ & 350 & 450 & 600 & 800 \\
\hline Thermal tolerance temperature of capacitors $\left({ }^{\circ} \mathrm{C}\right)$ & 120 & 140 & 150 & 175 \\
\hline Master frequency of multi-core locked step MCU & N/A & $300 \mathrm{MHz}$ & $600 \mathrm{MHz}$ & $1000 \mathrm{MHz}$ \\
\hline
\end{tabular}




\subsection{Core material Technology Innovation of the Electric Drive System}

In the electric drive system, the development of rare earth PM materials contributes to the PMSM development. The magnet performance characteristics have been significantly improved, such as magnetic energy product, magnetic declination, sinusoidal magnetization, magnet block splitting and bonding, light rare earth element usage, surface coating, and PM measurement. The grade over N50UH Nd-Fe-B PM is mass-produced, and its residual magnetism is close to $90 \%$ of the theoretical limit of $\mathrm{Nd}_{2} \mathrm{Fe}_{14} \mathrm{~B}$ compound. However, the coercivity is still lower than $30 \%$ of the theoretical limit, so there is much room for improvement.

Heavy rare earth grain boundary diffusion and grain boundary modulation technologies can be adopted for future development, as shown in Fig. 11. These technologies can greatly reduce the usage of heavy rare earth materials like dysprosium and/or terbium and improve the performance and quality of magnets. Moreover, some mixed PM materials (including ferrite) are used for partially replacing Nd-Fe-B materials by some OEMs like Toyota and GM.

Therefore, besides PM materials, corona guard insulation materials, electromagnetic wires, high-performance magnetic materials, and manufacturing processing have drawn much attention in the electric motor industries. Insulating materials and their insulation structure design, providing high performance, high reliability, high electric and thermal life, high thermal conductivity, corona guard, and oil compatibility, are also paid considerable attention since the high-speed motor and the high-frequency inverter are the development trend.

\subsection{Innovation of Power Electronics}

In the electric drive system, power electronics plays an important role in the traction motor system and electric powertrain performance. In the future, the NEV industry will focus on the following power electronics research.

(1) The trench technology has become the mainstream in IGBT chips for vehicle applications. It can enhance the ability of electron injection and reduce the switchingon, turning-off, and conduction losses. With the development of groove technology, the refinement of groove plays a key role in improving the overall performance of IGBT chips for EVs.

(2) Rapid thick epitaxial growth and the material inspection technology is drawing much attention for $\mathrm{SiC}$ MOSFET chips. Wafer preparation and inspection as well as low-sensitivity and high-density $\mathrm{SiC}$ or $\mathrm{GaN}$ module packaging are directly related to successful
NEV application on the third-generation WBG power semiconductors.

(3) Single-chip functional integration improvement, system complexity reduction, power density increase, and reliability improvement of power electronic chips and packages are focused. IGBTs or SiC MOSFETs and $\mathrm{SiC}$ diodes are integrated on the same chip to improve the current density of the power module. Current and temperature sensors are integrated on the electronic power switch chip to detect transient output current and transient junction temperature fluctuations, thus improving the reliability and power density of package modules.

(4) The technologies of copper binding wire, copper terminal direct bonding, belt bonding and flexible connection are adopted to replace the traditional aluminum binding wire technology. The contact area of the silicon wafer is increased for evenly distributing the thermoelectric stress in the power contact part, reducing the peak temperature of the silicon wafer and improving the power cycle life of the module.

(5) Double-side welding, single-side/double-side cooling, and integrating heat dissipation sink can reduce the thermal resistance of the chip, improve the heat dissipation capacity, and improve the power cycle reliability, which has become a new trend of the packaging technologies of the next-generation IGBT and $\mathrm{SiC}$ MOSFET module.

\subsection{Innovation of the Motor and Powertrain System}

In the domestic market of passenger BEV powertrains, the integration products of 3-in-1 and multi-in-1 electric drive assembly are at the same level as those of the global suppliers. Tesla's integrated structure design is relatively advanced and is based on the new electric chassis design and forward research. The specific power of motors exceeds $4-4.6 \mathrm{~kW} / \mathrm{kg}$ globally. However, there is no first-mover advantage at the time of product launch. To improve the driving efficiency, the SiC MOSFET inverters with discrete devices were commercialized earlier than others, and their highest efficiency of the 3-in-1 electric drive system is approximately $94 \%$. Compared with the Si-based motor drive system, powertrains based $\mathrm{SiC}$ provided higher peak and operating efficiencies under the vehicle driving cycles.

In the future, the systematic integration and supplier chain innovation of NEV electric powertrains and their key components should be focused, which include:

(1) Configuration technology of electromechanical coupling assembly; 
(2) Sealing (condensation), heat dissipation, and lubrication of highly integrated electromechanical coupling systems;

(3) Key parts and components such as shaft with gears, clutch, planetary gears, and actuators;

(4) Direct drive hub motor, new-type wheel hub electric drive system, and innovative design technology of the brake system;

(5) NVH design, noise suppression, detection, and evaluation technology;

(6) Validation standards and specifications for electromechanical coupling devices.

\subsection{1-2035 Technology Roadmap of Electric Powertrains, Key Components, and Materials}

The technology roadmap of electric powertrains, electric motors, power electronics converters, and key components, as well as materials, is described in Ref. [75]. The future performance parameters of the electric drives, their subassembly, parts/components, and materials are predicted and shown in Table 10 in terms of time frame.

\section{Conclusions}

The current states of the NEV motor systems and powertrain technologies are systematically reviewed; the technological innovations and applications in materials, devices, and powertrains are summarized in details; and different control algorithms are compared. Although the performances of traction motor and powertrain products is dramatically improved, more R\&D is required for more innovative technologies, such as motor design optimizations and control algorithms, multi-physical simulation analysis, robustness design, system integration with jointly considered motors, controllers and reducers/transmissions, a next-generation motor system based on $\mathrm{SiC}$ devices, PM motors with less or without heavy rare earth PM materials, efficient motor cooling methods, and new material development and applications.

Vehicular dynamic performances, energy saving features, safety, and comfortabilities are mainly summarized from the electric drive systems. The technical roadmaps of electric powertrains, traction motor systems, key components, and materials are summarized in terms of the time frame of 2025,2030 , and 2035, which can be used as a reference by researchers and engineers in the OEMs and NEV industry supplier chains, the government officers, or investors for investing strategies.

Acknowledgements We are grateful to Maotong Yang and Guanning Guo from the Institute of Electrical and Power Electronics Engineering at Harbin University of Science and Technology for their help in translating figures and tables as well as partial content of this paper.

\section{Compliance with Ethical Standards}

Conflict of interest On behalf of all authors, the corresponding author states that there is no conflict of interest.

Open Access This article is licensed under a Creative Commons Attribution 4.0 International License, which permits use, sharing, adaptation, distribution and reproduction in any medium or format, as long as you give appropriate credit to the original author(s) and the source, provide a link to the Creative Commons licence, and indicate if changes were made. The images or other third party material in this article are included in the article's Creative Commons licence, unless indicated otherwise in a credit line to the material. If material is not included in the article's Creative Commons licence and your intended use is not permitted by statutory regulation or exceeds the permitted use, you will need to obtain permission directly from the copyright holder. To view a copy of this licence, visit http://creativecommons.org/licenses/by/4.0/.

\section{References}

1. Li, Z., Khajepour, A., Song, J.: A comprehensive review of the key technologies for pure electric vehicles. Energy 182, 824-839 (2019)

2. Zou, Y., Wei, S., Sun, F., Hu, X., Shiao, Y.: Large-scale deployment of electric taxis in Beijing: a real-world analysis. Energy 100, 25-39 (2016)

3. Du, J., Li, F., Li, J., Wu, X., Song, J., Zou, J., Ouyang, M.: Evaluating the technological evolution of battery electric buses: China as a case. Energy 176, 309-319 (2019)

4. Sun, X., Li, Z., Wang, X., Li, C.: Technology development of electric vehicles: a review. Energies 1(13), 90 (2020)

5. Du, J., Ouyang, M., Wu, X., Meng, X., Li, J., Li, F., Song, Z.: Technological direction prediction for battery electric bus under influence of China's new subsidy scheme. J. Clean. Prod. 222, 267-279 (2019)

6. Kumar, P.R., Alok, K.: Adoption of electric vehicle: a literature review and prospects for sustainability. J. Clean. Prod. 253, 119911 (2020)

7. China association of automobile manufacturers: Economic performance of the automotive industry in November 2019, (2020-0525). http://www.autostats.org.cn/ReadArticle.asp?NewsID $=10672$

8. Lopez, I., Ibarra, E., Matallana, A., Andreu, J., Kortabarria, I.: Next generation electric drives for HEV/EV propulsion systems: technology, trends and challenges. Renew. Sustain. Energy Rev. 114, 109336 (2019)

9. Zhu, Z.Q., Howe, D.: Electrical machines and drives for electric, hybrid, and fuel cell vehicles. Proc. IEEE 4(95), 746-765 (2007)

10. Salem, A., Narimani, M.: A review on multiphase drives for automotive traction applications. IEEE Trans. Transp. Electrif. 4(5), 1329-1348 (2019)

11. Thomas, V.J., Maine, E.: Market entry strategies for electric vehicle start-ups in the automotive industry-lessons from Tesla motors. J. Clean. Prod. 235, 653-663 (2019)

12. Lee, W., Li, S., Han, D., Sarlioglu, B., Minav, T.A., Pietola, M.: A review of intergrated motor drive and wide-bandgap power electronics for high-performance electro hydrostatic actuators. IEEE Trans. Transp. Electrif. 3(4), 684-693 (2018)

13. Chau, K.T., Chan, C.C., Liu, C.: Overview of permanent-magnet brushless drives for electric and hybrid electric vehicles. IEEE Trans. Ind. Electron. 6(55), 2246-2257 (2008) 
14. Chan, C.C.: The state of the art of electric, hybrid, and fuel cell vehicles. Proc. IEEE 4(95), 704-718 (2007)

15. Wang, S., Deng, C.: Research on electric motor technologies for electric vehicles. Micro Motor (Servo Technology in Chinese) 39(8), 83-85(2006)

16. Yang, Z., Shang, F., Brown, I.P., Krishnamurthy, M.: Comparative study of interior permanent magnet, induction, and switched reluctance motor drives for EV and HEV applications. IEEE Trans. Transp. Electrif. 3(1), 245-254 (2015)

17. Uglielmi, P.: Comparison of induction and PM synchronous motor drives for EV application including design examples. IEEE Trans. Ind. Appl. 6(48), 2322-2332 (2012)

18. Zeraoulia, M., Benbouzid, M.E.H., Diallo, D.: Electric motor drive selection issues for HEV propulsion systems: a comparative study. IEEE Trans. Veh. Technol. 6(55), 1756-1764 (2006)

19. Zhao, X., Niu, S., Zhang, X., Fu, W.: A new relieving-DC-saturation hybrid excitation Vernier machine for HEV starter generator. IEEE Trans. Ind. Electron. 8(67), 6342-6353 (2020)

20. Zhu, X., Jiang, M., Xiang, Z., Quan, L., Hua, W., Cheng, M.: Design and optimization of a flux-modulated permanent magnet motor based on an airgap-harmonic-orientated design methodology. IEEE Trans. Ind. Electron. 7(67), 5337-5348 (2020)

21. Cha, K.S., Kim, D.M., Jung, Y.H., Lim, E.S.: Wound field synchronous motor with hybrid circuit for neighborhood electric vehicle traction improving fuel economy. Appl. Energy 263, 114618 (2020)

22. Xu, Q., Sun, J., Yang, Y., Tao, T., Cui, S.: Electromagnetic optimization design of compound-structure permanent-magnet motor for hybrid electric vehicle. Trans. China Electrotech. Soc. v1(35), 126-135 (2020)

23. Chen, Y., Zhu, X., Quan, L., Han, X., He, X.: Parameter sensitivity optimization design and performance analysis of double-salient permanent-magnet double-stator machine. Transa. China Electrotech. Soc. 8(32), 160-168 (2017)

24. Zheng, P., Lei, Y., Wu, F., Sui, Y., Wang, P.: Analysis and design of a six-phase fault-tolerant PM machine used for EVs. Electr. Mach. Control 6(17), 29-36 (2013)

25. Cai, W., Fulton, D., Congdon, C., Multi-set rectangular copper hairpin windings for electric machines, US Patent US6894417 B2

26. Matsuki, Y., Doki, S.: High stability V/f control of PMSM using state feedback control based on n-t coordinate system. International Power Electronics Conference, pp. 2224-2228

27. Tu, W., Xiao, G., Suo, C., Yang, K.: A design of sensorless permanent magnet synchronous motor drive based on V/f control. 2017 20th International Conference on Electrical Machines and Systems (ICEMS). 2017 pp. 1-5

28. Gu, L., Zhang, H.-L., Wang, Z.: An improved UDE-based fluxweakening control strategy for IPMSM. Energies 12, 4077 (2019)

29. Hu, J., Jia, M., Xiao, F., Fu, C., Zheng, L.: Motor vector control based on speed-torque-current map. Appl. Sci. 10, 78 (2019)

30. Li, G., Hu, J., Li, Y., Zhu, J.G.: An improved model predictive direct torque control strategy for reducing harmonic currents and torque ripples of five phase permanent magnet synchronous motors. IEEE Trans. Ind. Electron. 66, 5820-5829 (2018)

31. Sekour, M.H., Hartani, K., Merah, A.: Electric vehicle longitudinal stability control based on a new multimachine nonlinear model predictive direct torque control. J. Adv. Transp. 2017, 1-19 (2017)

32. Justo, J.J., Mwasilu, F., Kim, E., Kim, J., Choi, H.H., Jung, J.: Fuzzy model predictive direct torque control of IPMSMs for electric vehicle applications. IEEE/ASME Trans. Mechatron. 4(22), 1542-1553 (2017)

33. Jia, Y., Xu, N., Chu, L., Zhang, L., Zhao, D., Li, Y., Yang, Z.: Power flow control strategy based on the voltage vector distribution for a dual power electric vehicle with an open-end winding motor drive system. IEEE Access 6, 54910-54926 (2018)
34. Zhao, J., Hua, M., Liu, T.: Research on a sliding mode vector control system based on collaborative optimization of an axial flux permanent magnet synchronous motor for an electric vehicle. Energies 11(11), 1-16 (2018)

35. Liu, B., Zhao, Y., Hu, H.Z.: Structure-variable sliding mode control of interior permanent magnet synchronous motor in electric vehicles with improved flux-weakening method. Adv. Mech. Eng. 10, 168781401770435 (2018)

36. Dong, Y., Qin, H., Fu, D., Xu, H., Yan, Y.: Research and application of wide gap devices in electric vehicles. J. Power Supply 4(14), 119-127 (2016)

37. Iradukunda, A., Huitink, D.R., Luo, F.: A review of advanced thermal management solutions and the implications for integration in high-voltage packages. IEEE J. Emerg. Sel. Top. Power Electron. 1(8), 256-271 (2020)

38. Wang, Z., Shi, X., Tolbert, L.M., Wang, F., Liang, Z., Costinett, D., Blalock, B.J.: A high temperature silicon carbide mosfet power module with integrated silicon-on-insulator-based gate drive. IEEE Trans. Power Electron. 3(30), 1432-1445 (2015)

39. Wang, J., Li, Y., Han, Y.: Integrated modular motor drive design with GaN power FETs. IEEE Trans. Ind. Appl. 4(51), 3198-3207 (2015)

40. Zhang, Z., Wang, F., Tolbert, L.M., Blalock, B.J., Costinett, D.J.: Evaluation of switching performance of SiC devices in PWM inverter-fed induction motor drives. IEEE Trans. Power Electron. 10(30), 5701-5711 (2015)

41. Gong, X., Ferreira, J.A.: Comparison and reduction of conducted EMI in SiC JFET and Si IGBT-based motor drives. IEEE Trans. Power Electron. 4(29), 1757-1767 (2014)

42. Gong, X., Josifović, I., Ferreira, J.A.: Modeling and reduction of conducted EMI of inverters with SiC JFETs on insulated metal substrate. IEEE Trans. Power Electron. 7(28), 3138-3146 (2013)

43. Velander, E., Bohlin, G., Wiik, S.Å.T., Botling, F., Lindahl, M., Zanuso, G., Nee, H.: An ultralow loss inductorless \$dv/dt\$ filter concept for medium-power voltage source motor drive converters with $\mathrm{SiC}$ devices. IEEE Trans. Power Electron. 7(33), 6072-6081 (2018)

44. Han, D., Lee, W., Li, S., Sarlioglu, B.: New method for common mode voltage cancellation in motor drives: concept, realization, and asymmetry influence. IEEE Trans. Power Electron. 2(33), 1188-1201 (2018)

45. Wang, R., Liang, L., Chen, Y., Kang, Y.: A single voltage-balancing gate driver combined with limiting snubber circuits for series-connected SiC MOSFETs. IEEE J. Emerg. Sel. Top. Power Electron. 1(8), 465-474 (2020)

46. Li, K., Bouscayrol, A., Han, S., Cui, S.: Comparisons of electric vehicles using modular cascade machines system and classical single drive electric machine. IEEE Trans. Veh. Technol. 1(67), 354-361 (2018)

47. Ahn, K., Bayrak, A.E.: Papalambros: electric vehicle design optimization: integration of a high-fidelity interior-permanent-magnet motor model. IEEE Trans. Veh. Technol. 9(64), 3870-3877 (2015)

48. Zhang, L., Fan, Y., Lorenz, R.D., Nied, A., Cheng, M.: Design and comparison of three-phase and five-phase FTFSCW-IPM motor open-end winding drive systems for electric vehicles applications. IEEE Trans. Veh. Technol. 1(67), 385-396 (2018)

49. Zhai, L., Sun, T., Wang, J.: Electronic stability control based on motor driving and braking torque distribution for a four in-wheel motor drive electric vehicle. IEEE Trans. Veh. Technol. 6(65), 4726-4739 (2016)

50. Guo, B., Chen, Y.: Robust adaptive fault-tolerant control of fourwheel independently actuated electric vehicles. IEEE Trans. Ind. Inf. 5(16), 2882-2894 (2020)

51. Dizqah, A.M., Lenzo, B., Sorniotti, A., Gruber, P., Fallah, S., Smet, J.D.: A fast and parametric torque distribution strategy for 
four-wheel-drive energy-efficient electric vehicles. IEEE Trans. Ind. Electron. 7(63), 4367-4376 (2016)

52. Wang, Z., Qu, C., Zhang, L., Xue, X., Wu, J.: Optimal component sizing of a four-wheel independently-actuated electric vehicle with a real-time torque distribution strategy. IEEE Access 6, 4952349536 (2018)

53. Zhou, H., Jia, F., Jing, H., Liu, Z., Güvenç, L.: Coordinated longitudinal and lateral motion control for four wheel independent motor-drive electric vehicle. IEEE Trans. Veh. Technol. 5(67), 3782-3790 (2018)

54. Lee, W., Jeoung, H., Park, D., Kim, N.: An adaptive concept of PMP-based control for saving operating costs of extended-range electric vehicles. IEEE Trans. Veh. Technol. 12(68), 11505-11512 (2019)

55. Karvountziskontakiotis, A., Andwari, A.M., Pesyridis, A., Russo, S., Tuccillo, R., Esfahanian, V.: Application of micro gas turbine in range-extended electric vehicles. Energy 147, 351-361 (2018)

56. Rahman, K.M., Jurkovic, S., Stancu, C.C., Morgante, J.C., Savagian, P.J.: Design and performance of electrical propulsion system of extended range electric vehicle (EREV) chevrolet volt. IEEE Trans. Ind. Appl. 3(51), 2479-2488 (2015)

57. Li, J., Jin, X., Xiong, R.: Multi-objective optimization study of energy management strategy and economic analysis for a rangeextended electric bus. Appl. Energy 194, 798-807 (2017)

58. Li, J., Wang, Y., Chen, J., Zhang, X.: Study on energy management strategy and dynamic modeling for auxiliary power units in range-extended electric vehicles. Appl. Energy 194, 363-375 (2017)

59. Chen, Q.: Prospects for electric, hybrid and fuel cell vehicles. J. Autom. Saf. Energy 1(2), 12-24 (2011)

60. Emadi, A., Rajashekara, K., Williamson, S.S., Lukic, S.M.: Topological overview of hybrid electric and fuel cell vehicular power system architectures and configurations. IEEE Trans. Veh. Technol. 3(54), 763-770 (2005)

61. Chen, B., Evangelou, S.A., Lot, R.: Series hybrid electric vehicle simultaneous energy management and driving speed optimization. IEEE/ASME Trans. Mechatron. 6(24), 2756-2767 (2019)

62. Luo, C., Shen, Z., Evangelou, S., Xiong, G., Wang, F.: The combination of two control strategies for series hybrid electric vehicles. IEEE/CAA J. Autom. Sin. 2(6), 596-608 (2019)

63. Kim, D., Benoliel, P., Kim, D., Lee, T.H., Park, J.W., Hong, J.: Framework Development of series hybrid powertrain design for heavy-duty vehicle considering driving conditions. IEEE Trans. Veh. Technol. 7(68), 6468-6480 (2019)
64. Al-Adsani, A.S., Beik, O.: Design of a multiphase hybrid permanent magnet generator for series hybrid EV. IEEE Trans. Energy Convers. 3(33), 1499-1507 (2018)

65. Kong, H., Fang, Y., Fan, L., Wang, H., Zhang, X., Hu, J.: A novel torque distribution strategy based on deep recurrent neural network for parallel hybrid electric vehicle. IEEE Access 7, 65174 65185 (2019)

66. Tian, X., He, R., Sun, X., Cai, Y., Xu, Y.: An ANFIS-based ECMS for energy optimization of parallel hybrid electric bus. IEEE Trans. Veh. Technol. 2(69), 1473-1483 (2020)

67. Li, X., Evangelou, S.A.: Torque-leveling threshold-changing rulebased control for parallel hybrid electric vehicles. IEEE Trans. Veh. Technol. 7(68), 6509-6523 (2019)

68. Niu, G., Shang, F., Krishnamurthy, M., Garcia, J.M.: Design and analysis of an electric hydraulic hybrid powertrain in electric vehicles. IEEE Trans. Transp. Electrif. 1(3), 48-57 (2017)

69. Yang, C., Shi, Y., Li, L., Wang, X.: Efficient mode transition control for parallel hybrid electric vehicle with adaptive dual-loop control framework. IEEE Trans. Veh. Technol. 2(69), 1519-1532 (2020)

70. Kabalan, B., Vinot, E., Yuan, C., Trigui, R., Dumand, C., Hajji, T.E.: Efficiency improvement of a series-parallel hybrid electric powertrain by topology modification. IEEE Trans. Veh. Technol. 12(68), 11523-11531 (2019)

71. Qi, B., Liu, W., Zhang, L., Jia, Q., Li, S., Liu, B.: Innovative design and coordinated control of multi-mode coupling drive system with a speed-up clutch for plug-in hybrid electric vehicles, 2019 IEEE 28th International Symposium on Industrial Electronics (ISIE). IEEE, 2019, pp. 1875-1880

72. Ma, Z., Murgovski, N., Egardt, B., Cui, S.: Comprehensive analysis and optimal configurations of the EVT powertrain. IEEE Trans. Veh. Technol. 10(68), 9573-9587 (2019)

73. Liu, B., Wang, T., Wang, H., Li, L.: Nonlinear model predictive control for series-parallel hybrid electric buses. IEEE Access 7, 138792-138802 (2019)

74. Wang, M., Tong, C., Song, Z., Liu, J., Zheng, P.: Performance analysis of an axial magnetic-field-modulated brushless doublerotor machine for hybrid electric vehicles. IEEE Trans. Ind. Electron. 1(66), 806-817 (2019)

75. Cai, W., Gong, J., Zhang, Z., et al.: Chapter 7: Technology roadmap of electric drive. In: 《Technology Roadmap of Energy Saving and New Energy Vehicle》, China Machine Press. ISBN 9787-1111-67009-4, December 2020 